life of this child was saved by this manœuvre. It goes without saying that since prematurity is always suggestive of syphilis all caution must be used in adopting such a device.

In these ways we may endeavour to curtail the period of inanition and to minimise its ill effects. In the great majority of cases patience will be rewarded and the breast

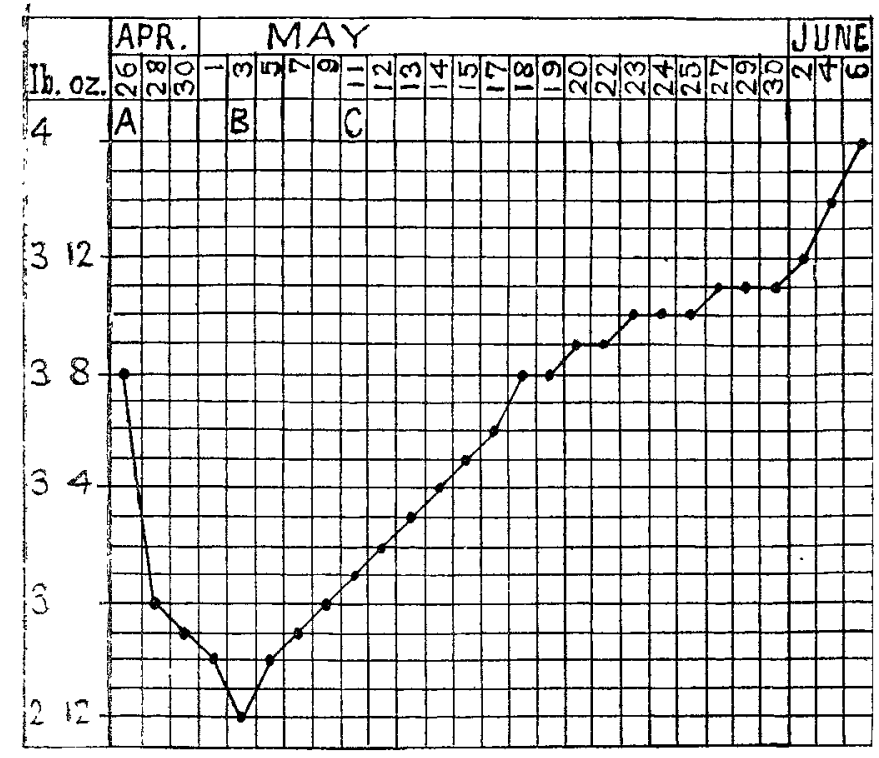

1, Mother's breast. B, Breast of woman in adjoining bed c, Returned to mother's breast.

secretion will have become established long before any disquieting symptoms appear. On the other hand, it is not to be denied that sometimes we shall fail. We must remember that in prolonged inanition the tolerance for food rapidly falls, and that if we wait until the infant is in a seriously depressed condition we shall be apt to find that the inanition becomes complicated by dyspepsia as soon as a more liberal supply of food is given. Symptoms which point to the advisability of giving more food are a rapid loss of weight uninfluenced by the measures described above, attacks of cyanosis or of syncope, and slowness, feebleness, or irregularity of the pulse. If it is decided to give some additional artificial food an attempt should be made to utilise the milk which has been drawn off by the breast pump after the infant has finished sucking. If this addition proves insufficient nothing remains but to give artificial food, preferably in the form of a single feed in the evening, while breast feeding is continued during the day. As a rule, bowever, but one result follows - a further decline in the amount of milk secreted-necessitating a further increase in the amount of the artificial food until the child is completely weaned. Inanition is of all degrees, and in the most severe cases, or when the cause at work is obstinate and persistent, we shall no doubt often fail; but that our failures will be greatly reduced in number by a true appreciation of the etiology of inanition and of the harm which may be done by unnecessary and premature interference there can, I think, be no doubt.

\section{SYPHILIS: ITS DANGERS TO THE COM- MUNITY, AND THE QUESTION OF STATE CONTROL. ${ }^{1}$}

\section{$\mathbb{B Y}$ H. C. FRENCH, M.R.C.S. ENG., L.R.C.P. LOND.,} MAJOR, ROYAL ARMY MEDICAL CORPS.

I HAVE the honour to address you on the subject of Syphilis: its Dangers to the Community, and the Question of State Control. The Section of Forensic Medicine (XIX.) is, as you know, acting jointly with that of Dermatology (XIII.) in discussing this difficult problem of our time, and all time, in the interest alike of the state and of the individual. The council of the Section of Forensic Medicine have requested me to deal mainly with the subject of State Control. This explains the brief reference to the first part of the subject under discussion.

The dangers to the community in Great Britain, however,

I A report presented at a joint session of the sections of Dermatology and yphilography and of Forensic Medicine at the Seventeent Eaternational Congress of Medicine, London, 1913. were very fully considered in a recent important discussion on syphilis, with special reference to its prevalence and intensity in the past and at the present day, its relation to public health, including congenital syphilis, and the treatment of the disease, held on June 10th, 17th, 24th, and July 8th, 1912, by the Royal Society of Medicine, London. This discussion extends to 214 pages of printed matter, and was published in the Proceedings of the Royal Society of Medicine in October, 1912, and later in book form. The debate dealt more with the dangers to the community in their general aspects, and no concrete scheme of State control was put forward as regards Great Britain, although such already exists in many of her colonies as well as in the Indian Empire for many years past (vide Appendix B). New York and Australia have recently taken the matter in hand.

The question of venereal diseases must soon become crucial in Great Britain under the Insurance scheme. If persons so suffering reap the benefits, what course is to be pursued in the case of those who do not report sick early, and develop complications causing prolonged invalidity as the result of concealment or delay in seeking treatment? Venereal diseases also must become notifiable in time, like ophthalmia neonatorum, by reason of the heavy cost to the State apart from all other considerations. If the principle is admitted of protecting the eyesight from the effects of gonorrhoea at birth, surely old age is entitled to a measure of protection against syphilis causing blindness due to optic nerve atrophy, and general paralysis of the insane. It is to be hoped, therefore, that some definite resolutions may now be drawn up by this Interna. tional Medical Congress, and an earnest attempt made to ensure legislative control of venereal diseases, a subject quite apart from the State regulation of vice. These diseases cost the country millions of pounds; they fill many homes with preventable misery, they overcrowd our workhouses, prisons, and lunatic asylums with imbeciles, idiots, criminals, epileptics, and other insane persons; they sap the vigour of the nation, and if uncontrolled may eventually endanger its very existence.

Dr. Holland, in 1854, estimated that in the United Kingdom there were at least a million and a half persons infected with syphilis each year. Dr. Mott states that possibly 3 to 4 per cent. of cases infected with syphilis are followed by parasyphilitic affections such as tabes and general paralysis. Further, we know that 11 per cent. of male private and 8 per cent. of male pauper admissions to lunatic asylums in Great Britain are due to this cause. The Wassermann reaction now throws a searchlight on idiocy, imbecility, and epilepsy, due to acquired or to congenital syphilis, which were not previously recognised as due to this cause. As the feeble-minded number 190,000 and certified insane persons 120,000 , the part played by syphilis in the causation of both conditions requires investigation. Dr. Le Noir gives 125,000 male syphilitics in Paris in the year 1899. Professor Fournier in 1899, judging by hospital practice, states that in Paris there are 17 syphilitics out of every 100 adult men. There is no reason to suppose, therefore, that a large city like London, without any control, and about 150 hospital beds, suffers less from this disease than Paris with 2000 beds, or Berlin. In both of these much smaller cities control and some means of segregation exist.

Taking the British Army as the only existing index to the relative prevalence in civil communities, as statistics of disease are available in the army but not in civil life, the average number of cases constantly on the syphilis register for two to three years and undergoing treatment is probably 3 to 4 per cent. of troops but numerous other cases have previously suffered, and have been struck off the syphilis register. The percentage of freshly contracted syphilis in my experience in the past few years is much higher amongst troops in England, more especially in London and Woolwich, than amongst those abroad. This is due to lack of control at the source and numerous other factors.

Dr. Bulkley has tabulated 110 epidemics of innocent syphilis with a total of 3000 victims. The causes of conveyance, apart from heredity, include " nursing, hand-rearing of infants, breast-drawing, accouchements, vaccinations, tattooing, household utensils, dental, barber's and other instruments, kissing, pipes, \&c." At Philadelphia recently there was an outbreak of eight cases of syphilitic chancres of the lip as the result of playing "kiss in the ring." Fournier, in Paris, found that fully 25 per cent. of all the females whom he had seen in private practice had 
contracted the disease innocently and undeservedly. Of the married females, in 75 per cent. of cases the disease was traced to the husband. Tarnowsky quotes the case of three families with 20 children, from whom only one healthy adult survived. This was in the intelligent class of society. At Moscow, Russia, in a period of ten years there were 2002 births from syphilised parents. Of these 1425 (71 per cent.) died. In regard to congenital syphilis, therefore, we are not justified in supposing that in England we stand on a separate pedestal.

As syphilis causes innumerable miscarriages and abortions, and gonorrhoea is responsible for a very large percentage of women's ailments, including sterility, it would appear that from a mere population point of view, as well as for the perpetuation of a healthy race, control of venereal diseases at the source has become absolutely essential. This is no longer a subject of purely academic interest, but perhaps the most important social problem of the day. In Chicago the Church is objecting to marry persons without a medical certificate of physical and mental fitness. It is considered that a large amount of unhappiness causing divorce is due to venereal diseases; and in this country it constitutes legal cruelty.

Professor Fournier states that syphilis does not only strike those who expose themselves to it, it strikes also and in a greater number those who do not expose themselves. It destroys infants by hecatombs, 48 per cent. in private practice in the city of Paris, and 84 per cent. in the St. Louis district. Is there not reason to suppose that half or one-third of the infants destroyed by syphilis this year would in 20 years have been soldiers? As regards innocently acquired and congenital syphilis, Dr. Bulkley, New York, states "that in Russian villages, where prostitution is unknown, syphilis decimates families, and is spread in an innocent manner." It is, therefore, not merely a question of letting the guilty suffer, but of death to the innocent. This is fully exemplified by infantile mortality, or later realised in the seclusion of insane asylums - or the retirement of the poor-house.

Alcohol unquestionably plays an important part in conducing to sexual immorality, and if disease is contracted in perpetuating syphilis and in causing relapse. In conjunction with syphilis alcohol is responsible for 27 per cent. of private and 31 per cent. of pauper male admissions to lunatic asylums in the United Kingdom. The view, however, is not concurred in that the reduction in venereal diseases in the British Army in recent years is due to the growth of temperance (vide Table IV.). A reduction in alcoholism was non-existent prior to 1907 in India. Venereal diseases, however, subsequent to the Cantonment Act, 1897, have steadily decreased every year until 1910, both as regards admission and constantly sick ratios. I do not acquiesce in the statement "that about 90 per cent. of infections take place while the victims are under the influence of alcohol." In order to arrive at an independent conclusion I have recently tabulated 461 cases of soldiers admitted to hospital under my care in the past year at Malta with freshly contracted venereal disease, and find that 203 were total abstainers ; 112 belonged to Section B Army Temperance, or consumed less than two pints of beer daily; 46 consumed three pints ; and 100 consumed over three pints a day. When due allowance is made for all these factors, it is not possible on the evidence to arrive at the conclusion that the great reduction of syphilis at Woolwich and Malta (Tables I. and II.), and of venereal diseases amongst 70,000 British troops in India, since 1897 (Tables III. and IV.), and in the

TABLE I.-Woolwioh, England: Syphilis In-patients (Local Troops) (Diagnosis and " Early Intensive" Treatment).

\begin{tabular}{|c|c|c|c|c|c|c|}
\hline \multirow{2}{*}{\multicolumn{2}{|c|}{ Year. }} & \multirow{2}{*}{$\begin{array}{l}\text { Average } \\
\text { daily } \\
\text { strength } \\
\text { of } \\
\text { garrison. }\end{array}$} & \multirow{2}{*}{$\begin{array}{l}\text { Admis- } \\
\text { sions- } \\
\text { actual } \\
\text { number. }\end{array}$} & \multirow{2}{*}{$\begin{array}{c}\text { Constantly } \\
\text { sick-actual } \\
\text { number in } \\
\text { hospital } \\
\text { daily. }\end{array}$} & \multicolumn{2}{|c|}{ Ratio per 1000 . } \\
\hline & & & & & Admissions. & $\begin{array}{c}\text { Constantly } \\
\text { sick. }\end{array}$ \\
\hline \multirow{5}{*}{ 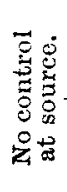 } & 11904 & 5311 & 331 & 56 & $62 \cdot 32$ & $10 \cdot 70$ \\
\hline & 1905 & 4966 & 202 & 30 & $41 \cdot 49$ & $6 \cdot 14$ \\
\hline & 1906 & 5096 & 129 & 14 & $25 \cdot 12$ & $2 \cdot 72$ \\
\hline & 1907 & 4702 & 87 & 13 & $18 \cdot 50$ & $2 \cdot \pi 1$ \\
\hline & 1908 & 5666 & 53 & 6 & $8 \cdot 75$ & 1.28 \\
\hline
\end{tabular}

1. Grey oil intramuscular mercurial injections for in-patients and in-patients as a general rule in early stages, and reserved mercurial grey oil injections for out-patients. 3. Soamin and arsacetin tried but discarded.

TABLE II._Syphilis : Malta Command.

\begin{tabular}{|c|c|c|c|c|c|c|c|c|}
\hline \multicolumn{2}{|c|}{ Year. } & 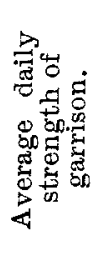 & 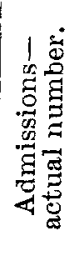 & 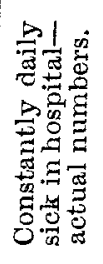 & 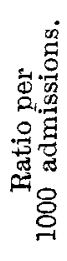 & 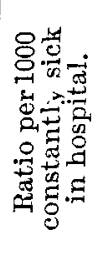 & 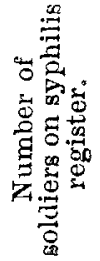 & 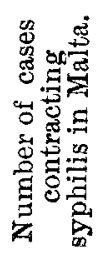 \\
\hline \multirow{4}{*}{ 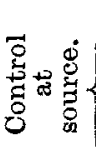 } & 1908 & 6030 & 112 & $14 \cdot 02$ & $18 \cdot 6$ & $2 \cdot 33$ & 158 & 89 \\
\hline & 1909 & 6392 & 125 & $12 \cdot 41$ & $19 \cdot 6$ & 1.94 & 171 & 87 \\
\hline & 1910 & 6769 & 83 & $9 \cdot 21$ & $12 \cdot 3$ & $1 \cdot 36$ & 160 & 35 \\
\hline & 1911 & 6686 & 29 & $2 \cdot 86$ & $4 \cdot 3$ & 0.42 & 146 & 11 \\
\hline
\end{tabular}

1. Confidential medical notification of venereal diseases was institnted in October, 1909. Diseased persons segregated and treated in
hospital. 2. In 1912 to May 31 st only five cases of syphilis of very mild type (attenuated) contracted in Malta amongst 7000 troops. 3. Treatment in 1908 and to September, 1909, intramuscular injections of grey oil. 4. In September, 1909, I instituted inunctions of ung. hydrarg.,
B.P., for in-patients in the early stages in ordinary cases, and reserved B.P., for in-patients in the early stages in ordinary cases, and r
grey oil injections for out-patients. 5. Salvarsan was not used.

\begin{tabular}{|c|c|c|c|c|c|}
\hline Year. & Strength。 & $\begin{array}{c}\text { Admissions } \\
\text {-ratio per } \\
1000 .\end{array}$ & $\begin{array}{c}\text { Constantly } \\
\text { sick-ratio } \\
\text { per } 1000 .\end{array}$ & $\begin{array}{l}\text { Invalids } \\
\text { sent home. }\end{array}$ & Deaths. \\
\hline \multirow{3}{*}{ 度密总 $\left\{\begin{array}{l}1895 \\
1896 \\
1897\end{array}\right.$} & 68,331 & $86 \cdot 8$ & 8.84 & 321 & 15 \\
\hline & 70,484 & $97 \cdot 7$ & $10 \cdot 47$ & 448 & 16 \\
\hline & 64,531 & $106 \cdot 2$ & $11 \cdot 65$ & 611 & 26 \\
\hline 1898 & 65,397 & $88 \cdot 2$ & $9 \cdot 51$ & 547 & 20 \\
\hline 1899 & 67,697 & $71 \cdot 9$ & $7 \cdot 54$ & 417 & 16 \\
\hline 1900 & 60,553 & $62 \cdot 5$ & 6.59 & 344 & 15 \\
\hline 1901 & 60,838 & $58 \cdot 3$ & 6.03 & 355 & 8 \\
\hline 1902 & 60,540 & $49 \cdot 9$ & 4.85 & 286 & 24 \\
\hline \begin{tabular}{l|l}
$\dot{0}$ & 1903
\end{tabular} & 69,613 & $46 \cdot 7$ & 5.04 & 190 & 12 \\
\hline 1904 & 70,413 & $49 \cdot 5$ & 5445 & 175 & 18 \\
\hline \begin{tabular}{l|l}
$\hat{8}$ & 1905
\end{tabular} & 70,994 & $35 \cdot 7$ & $4 \cdot 80$ & 75 & 13 \\
\hline 1906 & 70,193 & $27 \cdot \pi$ & $3 \cdot 55$ & 120 & 11 \\
\hline 1907 & 69,322 & $22 \cdot 2$ & $3 \cdot 02$ & 76 & 5 \\
\hline 1908 & 68,522 & $15 \cdot 8$ & $2 \cdot 37$ & 59 & - 3 \\
\hline 1909 & 71,556 & $16 \cdot 3$ & $2 \cdot 23$ & 26 & 2 \\
\hline 1910 & 72,491 & $14 \cdot 5$ & $2 \cdot 01$ & 18 & 1 \\
\hline
\end{tabular}

1. Control at the source (Cantonment Act) began October, 1897. The above figures deal with unquestionable syphilis. Out-patient treatment also began in 1898 for syphilis. Systematised in 1904. 2. Prior to 1904 all venereal sores, whether "soft chancre" or early "primary syphilis," were included under a heading Primary Syphilis in all Army Returns. I do not include them as soft chancres were not differentiated. 3 . Fron 1904 to 1910 syphilis and soft chancre are absolutely differentiated in British Army returns and registration of syphilis arranged. 4. Loss of service pay for venereal disease began in April, 1904. 5. Loss of proficiency pay for venereal disease began October, 1906. 6. Salvarsan not used.

TABLE IV.-India: Aamissions and Constantly Sick Katio per 1000 for "All Tenereal Diseases" and Alcoholism contrasted.

\begin{tabular}{|c|c|c|c|c|}
\hline \multirow[b]{2}{*}{ Year. } & \multicolumn{2}{|c|}{ Venereal diseases. } & \multicolumn{2}{|c|}{ Alcoholism. } \\
\hline & Admissions. & $\begin{array}{l}\text { Constantly } \\
\text { sick. }\end{array}$ & Admissions. & $\begin{array}{c}\text { Constantly } \\
\text { sick. }\end{array}$ \\
\hline 1898 & $303 \div 5$ & $27 \cdot 97$ & $3 \cdot 3$ & $0 \cdot 12$ \\
\hline 1899 & $250^{\circ} 4$ & $22 \cdot 55$ & $3 \cdot 1$ & $0 \cdot 12$ \\
\hline 1900 & $231 \cdot 3$ & $21 \cdot 19$ & $3 \cdot 7$ & $0 \cdot 14$ \\
\hline 1901 & $211 \cdot 5$ & $18 \cdot 35$ & $4 \cdot 4$ & 0.18 \\
\hline 1902 & $209 \cdot 6$ & $17 \cdot 60$ & $4 \cdot 4$ & 0.16 \\
\hline 1903 & $187 \cdot 3$ & 16.67 & $2 \cdot 4$ & $0 \cdot 11$ \\
\hline 1904 & $200 \cdot 4$ & $17 \cdot 63$ & $3 \cdot 1$ & $0 \cdot 14$ \\
\hline 1905 & $154 \cdot 3$ & $15 \cdot 37$ & $2 \cdot 8$ & 0.13 \\
\hline 1906 & $117 \cdot 4$ & $12 \cdot 32$ & $2 \cdot 4$ & $0 \cdot 11$ \\
\hline 1907 & $89 \cdot 9$ & $10 \cdot 61$ & $1 \cdot 3$ & 0.05 \\
\hline 1908 & $69-8$ & $8 \cdot 85$ & $1 \cdot 0$ & 0.04 \\
\hline 1909 & $67 \cdot 9$ & 8.52 & 0.9 & 0.03 \\
\hline 1910 & $58 \cdot 9$ & $7 \cdot 79$ & 0.5 & 0.02 \\
\hline
\end{tabular}

1. Control of venereal diseases at the source commenced October, 1897, 
Cantonment Act, India. 2. Service pay lost for admission to hospital for venereal diseases or alcoholism from April 1st, 1904. 3. Proficiency pay lost for armission to hospital for venereal diseases or alcoholism since October. 1906. 4. Note the yearly reduction of venereal disease from 1898 to 1910 (Paras. 1, 5, 6, 7). Alcoholism remained constant from 1898 to 1906 . From 1907 to 1910 the reduction is mainly due to (2) and (3). 5. Out-patient treatment of soldiers for syphilis which was instivuted in 1898 in some stations, was in 1904 made universal by regulation fn India and throughout the army generally. This does not apply to gonorrhnea and soft chancre, which are much reduced. 6. Changes of nomenclature of renereal diseases in 1904 ensured more accurate diagnosis of syphilis and the collection of statistics in 1904 was arranged on a better basis. 7. The Cantonment Act Amendment Act, 1895 (v. of 1895 ), Sect. 2, preclu ted the examination of prostitute women for the purposes of ascertaining whether they suffered from venereal diseases 470 in 1895, 444 in 1896, and 422 in 1897. The Cantonment Code of 1899 (in force since October, 1897) permits, in cantonments where troops are stationed, the examination and detention of diseased women (Para. 203, Appendix B). The admission ratio for "All Venereal Disease" consequently decre 'sed year by year until 1910, when it was only 58.9 per 1000. "The Constantly Sick" in hospital fell from 40.83 per 1000 in 1895 to $7 \cdot 79$ per 1000 in 1910 (vide Table V.). Surely a gratifying result which defies the criticism of all time. The decrease occurred in all
forms of venereal diseases-not only syphilis.

army generally, can be fairly attributed to increased temperance. The reduction is primarily due to early and effectual control of diseased persons, both men and women, as well as to registration of syphilis, disciplinary restrictions, systematising of statistics, and the confidential notification of disease and the application of initiative to meet the varying circumstances governing local conditions.

\section{State Control.}

Coming to the important question of prophylaxis, there are two essentially different modes of State intervention. First, the system known as Regulation, which implies registration and attendance of prostitute women. The second mode is "to require doctors and others to notify all cases of actually existing disease in persons in whatever class or sex to the health authority, who inquires into the means of segregation and treatment (as in the case of other infectious diseases), and is empowered to remove the patient to hospital if necessary." In the case of poor persons this implies a certain outlay for hospital accommodation and food, but it repays the State a hundredfold. Notification is not unequal Between men and women, nor does it unduly encourare immorality. Inquiries extending over 20 years in Brussels elicited the fact that amongst 1523 out of 3505 women the primary cause of prostitution was alleged by the women to be poverty.

A Royal Commission on the Blind, the Deaf, and the Dumb, which reported to both Houses of Parliament in the year 1889, estimated that about 7000 persons in the United Kingdom had lost their sight from ophthalmia neonatorum, and assessed the cost to the State for these cases of preventable blindness at $£ 350,000$ a year. This disease, which is commonly due to gonorrhca, is recently notifiable in some parts of Fingland.

It is interesting to trace the history of what has been done in this country. In 1896 the Secretary of State for the Home Department was approached with the object of appointing a Departmental Committee to inquire into the subject of the prevalence and the treatment of venereal disease amonost the population of England. The Government, whilst admitting the importance of the subject, did not think the time had arrived for taking action in the matter because there was not then a "sufficiently informed public opinion" on the disease to justify them in doing so. This alleged reason no longer remains as regards any disease, and the Insurance Act will prove that such a policy may be financially disastrous in regard to venereal diseases, as previously explained.

As the British Medical Journal pointed out in 1896, it would seem that in consequence of this state of things a considerable number of women do not receive proper treatment in the early stages of syphilis, and seek admission to various homes of refuge in London administered by ladies who devote their lives to work of charity of this kind. The ladies have been so deeply impressed with the extent of the misery caused by these maladies in young women that they associated themselves into a numerous and influential body, determined to do their utmost to secure measures as may be thought best, after due inquiry, to check the ravages of syphilis. The Council of the British Medical Association then appointed a committee, and urged on Her Majesty's Government the necessity for appointing a Departmental Committee to inquire: (1) As to the extent to which venereal disease prevails amongst the civil population of Great Britain, irrespective of its temporary increase or decrease; (Z) to collect information as to the present arrangement for the treatment of venereal diseases, the distribution of hospitals, and the number of beds available in different places, and to make suggestions as to the more efficient provision for the treatment of the disease ; (3) to collect suggestions and to express opinions as to the means that can be devised for preventing or limiting the spread of venereal disease among the civil population of this country.

The above resolution was also forwarded to the President of the International Congress on Venereal Diseases, which met at Brussels on Sept. 4th, 1899, urging the Congress to support the resolution by requesting the Governments of the respective delegates to pursue a similar investigation with a view of devising a uniform plan of action to mitigate the spread of this terrible disease among the people of Europe. This was finally embodied among the eight resolutions of the Congress. Further, the Royal College of Surgeons of England, in the annual report for the year 1897, contains a statement to the effect that the Council of the College had forwarded an address to the Secretary of State for India regarding the prevalence of venereal disease amongst the British troops in that country. In this address the Council observe: "We therefore express an earnest hope that Her Majesty's Government may take effective means to check the ravages of the disease (venereal) which not only undermines the constitutions of those who contract it in the first instance, but, by reason of the many ways in which it may be transmitted, destroys the health and happiness of countless persons, and induces in the children of those originally infected diseases of a most formidable character." So far as Fngland is concerned the matter äied a premature death, whilst "Nature breeds, perverse, all monstrous, all prodigious things," as in the age when Milton wrote.

As regards India, there was a meeting on this subject at St. Martin's Town-hall, London. "Admission was by ticket for which a charge was made, and nine-tenths of the audience were women." This effected the passage of the Cantonment Act, India, which came into force in October, 1897, with such marvellous results and stupendous saving to the Indian Government. India, therefore, must be our principal guide as to the effect of control at the source, as there are some 70,000 British troops always stationed there under more or less identical conditions. In India, in 1895 to 1897, and previously, there were 3000 soldiers constantly sick in hospital with venereal diseases (Table V.). These diseases

TABLE T.-India: Admissions and "Constantly Sick" Ratios per 1000 for " All Diseases" and "All Venereal Diseases" Contrasted.

\begin{tabular}{|c|c|c|c|c|c|c|}
\hline \multicolumn{2}{|c|}{ Year. } & $\begin{array}{l}\text { Average } \\
\text { strength. }\end{array}$ & $\begin{array}{c}\text { Admissions } \\
\text {-ratio per } \\
1000 \text { all } \\
\text { diseases. }\end{array}$ & $\begin{array}{l}\text { Admissions } \\
\text {-ratio per } \\
1000 \text { all } \\
\text { venereal } \\
\text { diseases. }\end{array}$ & $\begin{array}{c}\text { Constantly } \\
\text { sick-ratio } \\
\text { per } 1000 \\
\text { all diseases. }\end{array}$ & $\begin{array}{c}\text { Con- } \\
\text { stantly } \\
\text { sick-ratio } \\
\text { per 1000all } \\
\text { venereal } \\
\text { diseases. }\end{array}$ \\
\hline \multirow{3}{*}{ 总 } & (1895 & 68,331 & $1460^{\circ} 0$ & 470.0 & $93 \cdot 61$ & 40.83 \\
\hline & 1896 & 70,484 & $1386 \cdot 7$ & $444 \cdot 4$ & $93 \cdot 85$ & $39 \cdot 48$ \\
\hline & $(1897$ & 64,530 & $1500 \cdot 4$ & 422.5 & $101 \cdot 38$ & 39.41 \\
\hline \multirow{7}{*}{ 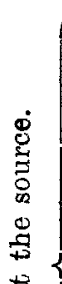 } & ( 1898 & 65,397 & $1454 \cdot 2$ & $303 \cdot 5$ & $90 \cdot 75$ & $27 \cdot 97$ \\
\hline & 1899 & 67,697 & $1148 \cdot 7$ & $250 \cdot 4$ & 73.00 & $22 \cdot 55$ \\
\hline & 1900 & 60,553 & $1143 \cdot 2$ & $231 \cdot 3$ & $71 \cdot 71$ & $21 \cdot 19$ \\
\hline & 1901 & 60,838 & $1104 \cdot 3$ & $211 \cdot 5$ & 669 & $18 \cdot 35$ \\
\hline & 1902 & 60,540 & $1078 \cdot 4$ & $209 \cdot 6$ & $66 \cdot 0$ & $17 \cdot 60$ \\
\hline & 1903 & 69,613 & $1035 \cdot 5$ & $187 \cdot 3$ & $63 \cdot 17$ & $16^{\circ} 67$ \\
\hline & 1904 & 70,413 & 897.0 & $200 \cdot 4$ & $57 \cdot 14$ & $17 \cdot 63$ \\
\hline \multirow{6}{*}{ 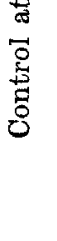 } & 1905 & 70,994 & $833 \cdot 6$ & $154 \cdot 3$ & $52 \cdot 41$ & $15 \cdot 37$ \\
\hline & 1906 & 70,193 & $871 \cdot 0$ & $117 \cdot 4$ & $51 \cdot 47$ & $12 \cdot 32$ \\
\hline & 1907 & 69,332 & $756 \cdot 4$ & $89 \cdot 9$ & $46 \cdot 38$ & 10.61 \\
\hline & 1908 & 68,522 & $836 \cdot 2$ & $69 \cdot 8$ & $45 \cdot 81$ & $8 \cdot 85$ \\
\hline & 1909 & 71,556 & 716.9 & $67 \cdot 9$ & $40 \cdot 26$ & $8 \cdot 52$ \\
\hline & 1910 & 72,491 & 576.5 & $58 \cdot 9$ & $31 \cdot 93$ & $7 \cdot 79$ \\
\hline
\end{tabular}

1. Control at the source, Cantonment Act, October, 1897 (bide Appen dix B). 2. Out-patient treatment of syphilis commenced in 1898 and was systematised by regulations in 1904 . Tl is does $n$ it, apply to gonor
rhoea and soft chancre, which are much reduced. 3. Loss of "service" 
pay in 1904 and proficiency pay 1906 for "venereal disease" in addition to the ordinary hospital stoppage of $7 d$. applicable to all diseases. 4. Ratios for venereal diseases yearly less. These diseases in recent years account for 20 to 26 per cent. of the "Constantly Sick" for "All Diseases," as contrasted with 40 to 45 per cent. in the years before control (1895-7).

caused 32 per cent. of the admissions and 42 per cent. of constantly sick in hospital from all diseases. These numbers, in 1910, have been reduced to 500 soldiers constantly sick in hospital, and venereal diseases caused only 10 per cent. of the admissions and 25 per cent. (1909, 20 per cent.) of the constantly sick in hospital from all diseases. This represents a yearly saving to that country of $£ 55,515$, when reckoned at $1 s$. per diem for hospital diet; and this quite apart from loss of service. During the same period the annual number of invalids from India to England for syphilis have been reduced from 611 in 1897 to 18 in 1910 . A trained soldier landed in India costs the State $£ 100$, so that the annual saving in invalids alone is enormous. Whereas in the United Kingdom in 1910, where no control at the source exists, venereal diseases in an average strength of 108,614 troops accounted for 31.8 per cent. of the constantly sick in hospital for all diseases. These latter figures probably indicate the average prevalerce in civil communities in the United Kingdom, but no statistics are kept in civil communities.

The paragraphs relating to sanitary prophylaxis in India are briefly given elsewhere (Appendix B), and the underlying principles considered in detail. ${ }^{2}$ The practical result has been that the Cantonment Act in conjunction with prophylaxis by treatment has effected an enormous reduction in India for all venereal diseases from 537 admissions per 1000 in 1895 to 59 admissions per 1000 in 1910. This demonstrates for all time the efficacy of adequate control (Tables III., IV., V.). In some British Colonies prophylactic methods already exist as regards control at the source. They support the good results obtained in India. Foreign medical opinion on this subject is given in Appendix A, India and Colonies, Appendix B. Briefly considered, some essential opinions in the control of prostitution and venereal diseases culled from 20 years' practical experience in many countries are as follows :-

1. Confidential medical notifioation of disease on primâfacie evidence and medical treatment for short periods in hospital in the early astively contagious stages of disease, the steps taken being dependent on environment and the circumstances of the individual case. As syphilis, five times out of six, is spread by clandestine prostitution, according to the experience of France, Belgium, and Germany, such notification by medical men more adequately meets this difficulty. Cases (without names) are reported to the health and police authorities when the exact address is known, and arrangements are then made for the segregation and treatment of diseased persons as in the case of other diseases. This was brought forward two years ago. ${ }^{3}$ I have practised it for three years at Malta with marked success (vide Table II.). The concrete scheme in Appendix B is vastly superior to a system of continental regulation, and has borne the test of 15 years.

2. The effectual control of openly practised prostitution by adequate police measures for irreclaimable prostitutes. Such control of openly practised prostitution is attended by incalculable benefit not only, to the women themselves but also to the civil community, in the reduction of venereal diseases and a reduction in the number of prostitutes. When control does not exist, or is temporarily removed, disease becomes as frequent among such women as amongst clandestines.

3. The rigid suppression of souteneurs who act as middlemen and live on the earnings of women, and even marry with this object in view. These men are often criminals of the worst description and levy blackmail on their clients whilst they batten on the poverty of the victims in their clutches. A valuable short Police Bill for the suppression of these men and the white slave traffic has recently become law in England. This will tend to prevent London being made the clearinghouse for Europe for prostitutes sent from other countries, or who move owing to disease.

4. The protection of orphan chldren and minors and the

2 Syphilis in the Army, 1907, Major H. C. French, R.A.M.C.

3 Brit. Med. Jour., Dec. 3rd, 1910; and The LA NCET, Nov. 18th, 1911. suppression of begging in the streets by children ander 12 years of age. This includes the suppression of women soutenours, who adopt orphan children to live on their immoral earnings when, from age or disease, they themselves have lost their charms. No girl under 21 years of age should be allowed to reside in a brothel in any capacity.

5. The suppression of loitering and solicitation in the streets by women or men acting on their behalf. This is possible in England under the Town Clauses Act, 1847. If men want prostitutes they must go and look for them where they lodge. This would lessen the work of the police, who are now obliged for hours at night to patrol in large numbers certain parts of the town. London is about the only European city where such a state of things exists. The public display of immorality discouraged in our theatres we encourage by the parade of prostitution in the streets. I recently read that some 70 per cent. of female prisoners are drawn from the unfortunate class. Surely a hospital, or a refuge, is more humane, as reclamation is possible.

6. The provision of "free voluntary dispensaries" where women who do not openly practise prostitution (clandestines) may be treated and reclaimed. These should be open at hours which are suitable to the working-class; this hour is usually the evening. Quite apart from the publicity involved, many poor persons cannot afford to wait in the outpatient department of the large hospitals for several hours. In addition to lock hospitals for irreclaimable women, I would advocate that sufficient beds be set aside for venereal diseases in everp large London hospital, and special courses of instruction arranged for the students, as in Paris.

7. Removal of disorderly persons from the towns, and measures to prevent the return of evicted persons, and to prevent harbouring of diseased prostitutes in brothels.

8. The control of diseased merchant seamen who spread the worst form of disease at seaport towns. This is quite feasible under Port Sanitary regulations, by making venereal diseases notifiable.

9. Control of persons seeking medical aid from chemists for venereal diseases, who spread their complaints broadcast and maintain syphilis in perpetuity. Civil practitioners should notify soldiers on the active list seeking medical aid at civil hospitals, as they commit an offence under the Army Act, spread disease, and increase military inefficiency. This is the law in Prussia.

10. Circumcision of male infants and of all recruits entering the army with phimosis is strongly advocated on Jewish and Mahommedan evidence; this markedly protects against syphilis, and minimises medical inefficiency.

11. Punishment by fine or imprisonment for concealing disease, or for transmitting it knowingly to another. The former exists in the army (King's Regulations, Paragraphs $465,504,505)$.

12. The marriage of syphilitics discouraged by law under ten years from date of contracting the disease.

Such measures may not completely deal with this difficult social problem, but they are the condensed experience of practical work as opposed to theoretical considerations. They are the bedrock on which an adequate superstructure can be laid. They do not conflict with public morality, but minimise disease, misery, and death. That the disease can be effectually controlled in a community is fully exemplified by personal experience of this work in India in 1896 to 1901 . Egypt, Malta, and England. The finding of a Royal Commission in England in 1870, and also in India, conclusively demonstrates the inestimable benefits derived from control and systematised effort (Appendix $\mathrm{C}$ ).

(To be continued.)

British Hospital for Mental Drsorders and Nervous Diseases ("Forbes Winslow MEMorial").-The secretary of this institution informs us that owing to the death of Dr. Forbes Winslow the hospital is under the management of a new lay executive committee and is being entirely reorganised. An increased medical staff has been appointed, and as soon as the lease expires new premises will be found. There have been on an average 3000 borderland cases treated annually, and it is hoped that under the new auspices the usefulness of this institution will be considerably increased. 